\title{
Psychological Effects of the Gardening Activity on Mother and Their Infant: Preliminary Evidence from an Exploratory Pilot Study
}

\author{
Yuka Kotozaki \\ Iwate Medical University, Iwate, Japan \\ Email: y-kotozaki@umin.ac.jp
}

How to cite this paper: Kotozaki, Y. (2020). Psychological Effects of the Gardening Activity on Mother and Their Infant: Preliminary Evidence from an Exploratory Pilot Study. Psychology, 11, 1349-1360. https://doi.org/10.4236/psych.2020.119087

Received: August 18, 2020

Accepted: September 20, 2020

Published: September 23, 2020

Copyright $\odot 2020$ by author(s) and Scientific Research Publishing Inc. This work is licensed under the Creative Commons Attribution-NonCommercial International License (CC BY-NC 4.0). http://creativecommons.org/licenses/by-nc/4.0/

\section{(c) (i) \& Open Access}

\begin{abstract}
The Gardening activity is regarded as effective in improving psychological function. However, the psychological effects of the infant from mothers who engage in gardening activity are not well known. This study conducted an exploratory pilot study to confirm the psychological effects of the gardening activity on mother and their infant. Fifteen postpartum women with infants under one-year-old participated in this study. They participated in eight gardening activities. This study asked mothers questions about their infant's emotional state, attachment to their infant, postpartum depression, and parenting stress before and after the gardening activity. $100 \%$ of the participants completed the gardening activity sessions. As a result, the rhythmicity score of the Revised Infant Temperament Questionnaire (RITQ), a measure of infant's emotional aspects was a significant increase than pre-test $(t=-2.827, p$ $=0.013)$. Attachment score was significantly improved than pre-test $(t=$ 2.432, $p=0.029$ ). Stress regarding parents score was also significantly improved than pre-test $(t=2.299, p=0.037)$. These findings provide evidence that the effects of gardening activities on the psychological effects of postpartum women and their infant. Future studies with larger subject cohorts are warranted to confirm the findings of this pilot exploratory study.
\end{abstract}

\section{Keywords}

Postpartum Women, Infant, Gardening Activity, Intervention, Psychological Change, Postpartum Care

\section{Introduction}

A mother's mental health is known to have a variety of effects on the child (Network NECCR, 1999; Olfson et al., 2003; Weissman et al., 1997; McLennan 
et al., 2001; Kahn et al., 2002). In other words, a mother's mental health is important for the healthy growth of the child. One of the most often mentioned mental health issues for mothers is postpartum depression. Many studies have suggested that women are more susceptible to depression during pregnancy and postpartum (Evans et al., 2001; Gavin et al., 2005; Pitt, 1968; Zaers et al., 2008). Previous studies have reported that the incidence and prevalence of postpartum depression is about 10\%, respectively (Pitt, 1968; Kumar \& Robson, 1984; O'Hara \& Swain, 1996). Although there are many efforts to improve postpartum depression (Rowan et al., 2015; Zinga et al., 2005; Kozhimannil et al., 2011; Simhi et al., 2019; Horowitz \& Goodman, 2005), many women who have postpartum depression often hesitate to consult a specialist due to the difficulty of going to the hospital with an infant or having trouble with medication while breastfeeding (Kozhimannil et al., 2011; Bilszta et al., 2010). Leaving postpartum depression untreated can increase the risk of it becoming severe or chronic (Dunkel \& Tanner, 2012; Brennan et al., 2000), so less burdensome measures for mother who have given birth is necessary. This study focused on gardening activities that can be easily carried out in one's garden or balcony planter at one's leisure because we believe that it is less burdensome for mothers who are taking care of their infants at home.

The gardening activity is based not only on the effects of a series of the gardening activity of growing, harvesting and incorporating them into life but also on the effect of the physical function being restored as well as the attachment to the plant (Hayashi et al., 2008; Gonzalez et al., 2010; Hansen-Ketchum et al., 2009; Maller et al., 2006; Page, 2008; Haller et al., 2019; Rappe, 2005). Additionally, the gardening activity is thought to have psychological improvement effects such as gaining self-confidence, sense of achievement, satisfaction, joy, and happiness, as well as relieving stress (Sempik et al., 2003; Ulrich et al., 1991); Although many studies have been conducted using the gardening activity with the children, adults, elderly, people with disabilities and ailing patient (Cimprich, 1993; Relf \& Dorn, 1995; Simon \& Straus, 1998; Cimprich \& Ronis, 2003; Kam \& Siu, 2010; Gonzalez et al., 2010; Kim et al., 2012; Kotozaki, 2014). Waliczek et al. reported that children's gardening activities could help children's self-esteem and stress reduction (Waliczek et al., 2000). Also, Eriksson et al. reported that five women with stress-related illnesses engaged in three months of gardening activities that resulted in positive moods and promoted gardening activities (Eriksson et al., 2010).

However, the psychological effects of gardening activity on postpartum women and their infants are unknown. This study aimed to clarify the psychological effects of the gardening activity on mother and their infant by an exploratory pilot study.

\section{Materials and Methods}

\subsection{Study Design}

The present study is a part of a project investigating the effects of gardening 
activities on postpartum women and their infants and was an exploratory pilot study. The Research Ethics Committee of Iwate Medical University approved all procedures (MH2018-512). This study registered at the University Hospital Medical Information Network (UMIN) Clinical Trials Registry (ID: UMIN000034331), written informed consent from all participants.

All procedures were performed under the Helsinki Declaration because our analyses were exploratory rather than hypothesis-driven, a priori power analysis not performed to determine the sample size.

\subsection{Study Subjects}

This study recruited 15 healthy women (mean age: $30.4 \pm 3.2$ years old) of about one year after childbirth recruited by newspaper advertisement. The consolidated standards of reporting trial (CONSORT) flowchart provided in Figure 1. There were 15 participants, and the response rate was $100 \%$. Their infant was cared for by nursery staff in a particular location while the mother did their gardening activity.

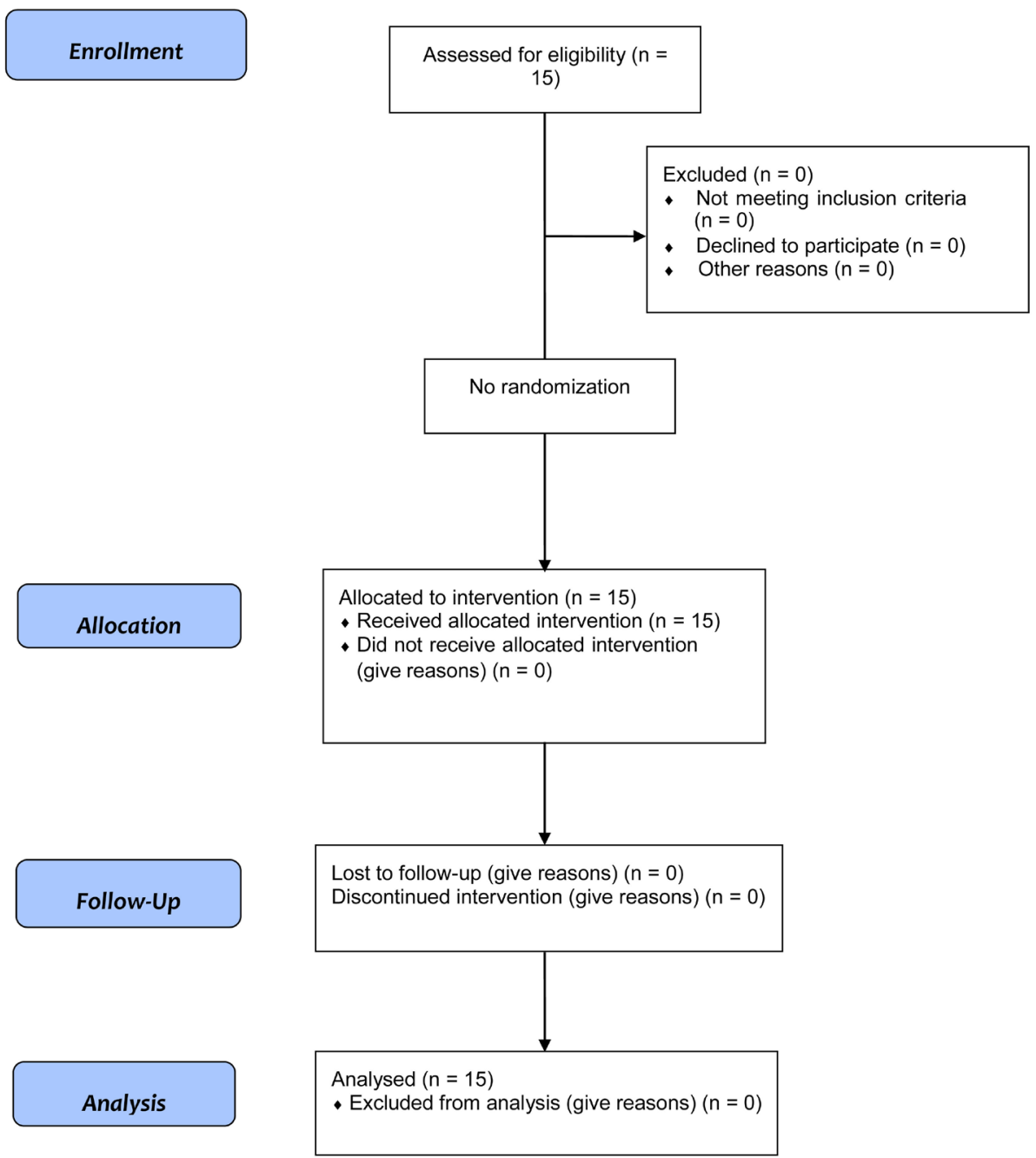

Figure 1. Consolidated standards of reporting trial (CONSORT) diagram. 


\subsection{Intervention}

Participants were asked to attend a total of eight gardening activities once a week at the lecture room of Iwate Medical University. The activity is guided by a facilitator with experience in leading community gardening activities. The facilitator was a gardener and gardening instructor for over ten years. In this gardening activity, participants planted and nurtured plants, weeded, gathered the flowers they grew, and made a herbarium from the plants they grew into dried flowers. This activity was not part of the ordinary farm work. The participants who attended to enjoy the experience and not learn how to play the gardening touched the plant. Each time the facilitator presented an actual plant, explaining it to the students and teaching them how to plant and care for it, and participants experienced touching, potting, and caring for the plants while listening to the facilitator's explanations. The facilitator checked the participants' work and modified it. Rather than giving the participants spoon-feed instructions, the facilitator gave them instructions, and the participants themselves corrected it did. Participants also did daily gardening activities at home using the same plants. Participants completed a series of psychological measurements before beginning the program schedule (Pre-test). After eight weeks, participants re-examined using the same psychological measurements (Post-test).

\subsection{Measurements}

The current study carried out the following measures in the pre- and post-test. The infant's temperament was assessed by the Japanese version of the Revised Infant Temperament Questionnaire (RITQ) (Kikuno \& Kikuno, 2015). This test includes 21-items and scored a four-point scale. The parents will answer the questionnaire. Adaptiveness, gustatory sensitivity, rhythmicity, frustration tolerance, visual sensitivity, persistence and persistence of attention, and tactile sensitivity will be assessed. The higher the score, the more it applies to them. The Japanese version of the Mother assessed the attachment-to-Infant Bonding Scale (MIBS-J) (Yoshida et al., 2012). This scale is a 10-item Likert-type questionnaire. A higher MIBS-J score indicates more negative feelings towards the infants. Postpartum depression was assessed by the Japanese version of the Edinburgh Postpartum Depression Scale (EPDS) (Okano et al., 1996). The EPDS is a commonly used tool to screen for depression symptoms, including anxiety, feelings of guilt, and dysphoria, during and after pregnancy. The 10-item self-reported questionnaire assessed the frequency of depressive symptoms over the previous seven days and scored using a four-point scale (from zero to three). A higher score indicates a higher degree of depressive symptoms. Postpartum stress was assessed by the Japanese version of the Parenting Stress Index (PSI) (Narama et al., 1999). The PSI includes 78 items classified into seven subscales for the stress regarding children (PSIc) and eight subscales for the stress regarding parents (PSIp). The PSI is scored on a five-point scale, with a higher score indicating a high parenting stress level. 


\subsection{Statistical Analyses}

Data analyses were carried out with SPSS version 25 (IBM Corp., Armonk, NY, USA). We used within-group t-tests to compare pre- and post-test. Statistical significance was designated as $p<0.05$.

\section{Results}

Participant characteristics are showed in Table 1. More than half of the participants (66.7\%) were in their 30s. About half of the participants (46.7\%) had a higher level of education. Also, $86.7 \%$ of participants were married at the time of the study. More than half of the participants $(53.3 \%)$ had their first birth. The average age of their infants was $6.9 \pm 3.0$ months.

The comparison of pre and post-test scores are showed in Table 2. Rhythmicity score of the RITQ was a significant increase than pre-test $(t=-2.827, p=$ 0.013 ). Also, MIBS-J of post-test was significantly improved than pre-test $(t=$ 2.432, $p=0.029$ ). EPDS score, PSIp subscale score, and competence as parent score in PSIp subscale of post-test was significantly improved than pre-test (EPDS: $t=3.659, p=0.003$; PSIp subscale: $t=2.299, p=0.037$; competence as parent score in PSIp: $t=2.765, p=0.015)$.

\section{Discussion}

The present study is the first to investigate the psychological effects of the gardening activity on mother and their infant by an exploratory pilot study. Consequently, the infants of mothers who engaged in gardening activities had better rhythmicity.

Table 1. Participant characteristics $(n=15)$.

\begin{tabular}{|c|c|}
\hline Variables & \\
\hline Age (mean $\pm \mathrm{SD})$ & $30.4 \pm 3.2$ \\
\hline \multicolumn{2}{|l|}{ Highest educational attainment (\%) } \\
\hline High school & 26.7 \\
\hline College & 26.7 \\
\hline University or more & 46.7 \\
\hline \multicolumn{2}{|l|}{ Marital status (\%) } \\
\hline Single & 6.7 \\
\hline Married & 86.7 \\
\hline Divorce & 6.7 \\
\hline \multicolumn{2}{|l|}{ Number of children (\%) } \\
\hline One & 53.3 \\
\hline Two & 33.3 \\
\hline Three or more & 13.3 \\
\hline Age of their infants (mean \pm SD months) & $6.9 \pm 3.0$ \\
\hline
\end{tabular}

SD, standard deviation. 
Table 2. RITQ, MIBS-J, EPDS, and PSI scores between pre- and post-test.

\begin{tabular}{|c|c|c|c|c|}
\hline & $\begin{array}{l}\text { pre-test, mean } \\
\text { (SD) }\end{array}$ & $\begin{array}{l}\text { post-test, mean } \\
\text { (SD) }\end{array}$ & $\mathrm{t}$ & $p$ value \\
\hline \multicolumn{5}{|l|}{ RITQ } \\
\hline Adaptiveness & $5.9(1.4)$ & $5.6(1.3)$ & 1.16 & 0.265 \\
\hline Gustatory sensitivity & $4.3(3.9)$ & $3.8(3.5)$ & 1.705 & 0.11 \\
\hline Rhythmicity & $5.3(1.8)$ & $6.2(2.2)$ & -2.827 & 0.013 \\
\hline Frustration tolerance & $5.4(1.5)$ & $5.2(1.5)$ & 0.764 & 0.458 \\
\hline Visual sensitivity & $5.1(1.8)$ & $4.9(1.6)$ & 0.487 & 0.634 \\
\hline Persistence and persistence of attention & $2.8(4.0)$ & $2.8(3.8)$ & 0 & 1 \\
\hline Tactile sensitivity & $5.1(2.1)$ & $5.2(2.2)$ & -0.292 & 0.774 \\
\hline MIBS-J & $11.4(1.4)$ & $9.6(2.4)$ & 2.432 & 0.029 \\
\hline EPDS & $2.8(2.7)$ & $1.3(2.5)$ & 3.659 & 0.003 \\
\hline \multicolumn{5}{|l|}{ PSI } \\
\hline PSIc & $58.9(16.7)$ & $59.1(18.8)$ & -0.076 & 0.941 \\
\hline Little effort to please parent & $9.8(2.2)$ & $9.5(1.8)$ & 0.807 & 0.433 \\
\hline Child mood displeased & $12.5(5.3)$ & $11.7(5.6)$ & 1.178 & 0.259 \\
\hline Child does not fulfill parent's expections & $7.2(3.6)$ & $7.3(3.3)$ & -0.269 & 0.792 \\
\hline Distractibility/hyperactivity & $11.9(5.5)$ & $12.7(4.9)$ & -0.732 & 0.476 \\
\hline Child follows parent/not accept & $6.8(2.7)$ & $7.3(3.5)$ & -0.953 & 0.357 \\
\hline Feel something is wrong with child & $5.0(1.8)$ & $5.2(2.1)$ & -0.612 & 0.55 \\
\hline Hypersensitivity/lack of adaptability & $5.7(2.8)$ & $5.4(2.7)$ & 0.845 & 0.413 \\
\hline PSIp & $76.3(23.2)$ & $72.3(22.9)$ & 2.299 & 0.037 \\
\hline Role restriction & $14.7(6.3)$ & $14.1(6.3)$ & 1.085 & 0.296 \\
\hline Social isolation & $11.0(3.8)$ & $10.5(3.7)$ & 0.798 & 0.438 \\
\hline Relationship with spouse & $9.6(4.8)$ & $9.5(4.7)$ & 0.695 & 0.499 \\
\hline Competence as parent & $18.1(4.3)$ & $16.2(4.2)$ & 2.765 & 0.015 \\
\hline Depression/sense of guilt & $6.3(4.0)$ & $5.5(2.8)$ & 1.468 & 0.164 \\
\hline Despondency after dischange & $6.5(3.0)$ & $6.4(3.0)$ & 0.323 & 0.751 \\
\hline Difficulty feeling attachment & $4.7(2.5)$ & $4.7(2.5)$ & 0 & 1 \\
\hline Health condition & $5.5(2.0)$ & $5.4(2.2)$ & 0.193 & 0.849 \\
\hline
\end{tabular}

SD, standard deviation. Statistical significant $(p<0.05)$. RITQ, Revised Infant Temperament Questionnaire; MIBS-J, The Japanese version of the Mother assessed the attachment-to-Infant Bonding Scale; EPDS, Edinburgh Postnatal Depression Scale; PSI, Parenting Stress Index; PCIc, the stress regarding children of PSI; PSIp, the stress regarding parents of PSI.

Also, maternal attachment, postpartum depression, and parenting stress improved after the gardening activity. These results may help in understanding what the gardening activity affect postpartum women and their infants.

One of the findings of this study was improving the infant's rhythmicity after the gardening activity. The gardening activity has been reported to improve so- 
cial aspects such as improved cooperativeness and time management skills and rhythmicity and improvements in mental health (Simon \& Straus, 1998; Relf \& Dorn, 1995). The children who have rhythmicity are more likely to have smooth parenting because their mothers are more likely to predict their children's behavior and regularly respond to their mothers' parenting (Kikuno \& Kikuno, 2015). In the present study, although the infants themselves did not participate in the gardening activity, it seems that gardening activity may have had a positive effect on the infant's rhythmicity due to the mother's psychological improvement and the changes in their responses to the infants.

The second thing this study revealed was that the mother's attachment to the baby increased after the gardening activity. The gardening activity has the effect of developing an attachment to plants (Page, 2008; Haller et al., 2019; Rappe, 2005). There seems to be an overlap between the act of growing plants and child-rearing in the "raising" part (Kim \& Park, 2016; Koga \& Iwasaki, 2018). A study of mothers with children between the ages of four and seven reported that mothers' gardening activity improved the mother-child relationship and led to positive changes (Kim \& Park, 2016). Growing plants and feeling the process of their growth in gardening activity will lead to a sense of attachment, accomplishment, and confidence (Kim \& Park, 2016). Also, in a study of the healing effects of greenery by text mining, the experience of healing was extracted from active involvement in "growing" and "decorating" plants (Koga \& Iwasaki, 2018). From an evolutionary psychological perspective, it has been reported that plants evoke strong positive emotions due to their longstanding relationship with food resources (Koga \& Iwasaki, 2018). The mothers who participated in this study also felt that the number of gardening activities overlapped with the plants and their children's development, and their feelings towards their infants may have also changed to more positive emotions.

The third finding of this study was that mothers' depression and parenting stress increased after gardening activity. However, there were no studies that used the gardening activity to improve mental health failure in postpartum women. The gardening activity with mothers with children aged from four to seven years has been reported to have significantly improved parenting stress levels after the gardening activity (Kim \& Park, 2016). The stress-reducing effects by using gardening activity have been reported in several previous studies (Francis \& Hester, 1992; Milligan et al., 2004; Gross \& Lane, 2007; Hayashi et al., 2008; Eriksson et al., 2010). Other studies have shown that gardening is related to a lower likelihood of depression (Teychenne et al., 2008). It has been reported that many of the reasons for gardening are relaxation and stress reduction (Dunnett \& Qasim, 2000; Armstrong, 2000; Clayton, 2007). Being in contact with plants through the gardening activity may help calm the mood and stabilize the mind, resulting in an improvement in stressful and depressive states. It might be said that gardening activity has had a similar effect on postpartum depression and parenting stress. 
There are several limitations to this study. First, since this study was an exploratory pilot study, the sample size was not set. Second, although this study was an exploratory pilot study and was set up as a single-armed study, it is susceptible to the influence of confounding factors for not providing the control condition. Alongside with revision of the program, future randomized control trials are required to validate the program's effectiveness. Third, a follow-up period was not established in this study because it was an exploratory pilot study. Fourth, this study is examining whether there is any change in horticultural activities over two months, and the sustainability of the effect is not an item to be examined. Finally, emotional change in the infants of this study was an objective assessment of the mother. Because infants are difficult to assess directly through questionnaires and other forms of assessment, it may be necessary in the future to consider using a visual assessment tool such as near-infrared spectroscopy (NIRS), for example. That point needs to be considered in the future.

In conclusion, this study provided preliminary evidence about the psychological effects of gardening activity on mother and their infant. The gardening activity may be used as excellent psychological care to help postpartum women and their infants stay healthy. Simple gardening activities at home as psychological support in the context of the current coronavirus disease 2019 (CODID-19) epidemic and simple gardening activities could be incorporated into workshops for postpartum women held by businesses and governments to create an environment in which postpartum women and their infants can readily participate and promote mental health care for mothers.

\section{Acknowledgements}

The author appreciates women who participated in the study and sincerely thanks Mrs. Teruko Tachibana, Mrs. Yoshiko Sasaki, and Mr. Shuto Kotozaki for study assistant and Oscar Reggie M.D. as study support.

\section{Funding}

This work was supported by the grants from the Scholarship Fund for Women Researchers in Japan.

\section{Conflicts of Interest}

The author declares no conflicts of interest regarding the publication of this paper.

\section{Availability of Data and Materials}

The datasets analyzed during the current study are available from the corresponding author on reasonable request.

\section{References}

Armstrong, D. (2000). A Survey of Community Gardens in Upstate New York: Implications for Health Promotion and Community Development. Health and Place, 6, 319-327. 
https://doi.org/10.1016/S1353-8292(00)00013-7

Bilszta, J., Ericksen, J., Buist, A., \& Milgrom, J. (2010). Women’s Experience of Postnatal Depression-Beliefs and Attitudes as Barriers to Care. Australian Journal of Advanced Nursing, 27, 44-54.

Brennan, P. A., Hammen, C., Andersen, M. J., Bor, W., Najman, J. M., \& Williams, G. M. (2000). Chronicity, Severity, and Timing of Maternal Depressive Symptoms: Relationships with Child Outcomes at Age 5. Developmental Psychology, 36, 759-766. https://doi.org/10.1037/0012-1649.36.6.759

Cimprich, B. (1993). Development of an Intervention to Restore Attention in Cancer Patients. Cancer Nursing, 16, 83-92. https://doi.org/10.1097/00002820-199304000-00001

Cimprich, B., \& Ronis, D. L. (2003). An Environmental Intervention to Restore Attention in Women with Newly Diagnosed Breast Cancer. Cancer Nursing, 26, 284-292. https://doi.org/10.1097/00002820-200308000-00005

Clayton, S. (2007). Domesticated Nature Motivations for Gardening and Perceptions of Environmental Impact. Journal of Environmental Psychology, 27, 215-224. https://doi.org/10.1016/j.jenvp.2007.06.001

Dunkel, S. C., \& Tanner, L. (2012). Anxiety, Depression and Stress in Pregnancy: Implications for Mothers, Children, Research, and Practice. Current Opinion in Psychiatry, 25, 141-148. https://doi.org/10.1097/YCO.0b013e3283503680

Dunnett, N., \& Qasim, M. (2000). Perceived Benefits to Human Well-Being of Urban Gardens. HortTechnology, 10, 40-45. https://doi.org/10.21273/HORTTECH.10.1.40

Eriksson, T., Karlström, E., Jonsson, H., \& Tham, K. (2010). An Exploratory Study of the Rehabilitation Process of People with Stress-Related Disorders. Scandinavian Journal of Occupational Therapy, 17, 29-39. https://doi.org/10.3109/11038120902956878

Evans, J., Heron, J., Francomb, H., Oke, S., \& Golding, J. (2001). Cohort Study of Depressed Mood during Pregnancy and after Childbirth. British Medical Journal, 323, 257-260. https://doi.org/10.1136/bmj.323.7307.257

Francis, M., \& Hester, R.T. (1992). The Meaning of Gardens: Idea, Place, and Action.

Gavin, N. I., Gaynes, B. N., Lohr, K. N., Meltzer-Brody, S., Gartlehner, G., \& Swinson, T. (2005). Perinatal Depression: A Systematic Review of Prevalence and Incidence. Obstetrics \& Gynecology, 106, 1071-1083. https://doi.org/10.1097/01.AOG.0000183597.31630.db

Gonzalez, M. T., Hartig, T., Patil, G. G., Martinsen, E. W., \& Kirkevold, M. (2010). Therapeutic Horti-Culture in Clinical Depression: A Prospective Study of Active Components. Journal of Advanced Nursing, 66, 2002-2013. https://doi.org/10.1111/j.1365-2648.2010.05383.x

Gross, H., \& Lane, N. (2007). Landscapes of the Lifespan: Exploring Accounts of Own Gardens and Gardening. Journal of Environmental Psychology, 27, 225-241. https://doi.org/10.1016/j.jenvp.2007.04.003

Haller, R., Kennedy, K., \& Capra, C. (2019). The Profession and Practice of Horticultural Therapy. Boca Raton: CRC Press. https://doi.org/10.1201/9781315143101

Hansen-Ketchum, P., Marck, P., \& Reutter, L. (2009). Engaging with Nature to Promote Health: New Directions for Nursing Research. Journal of Advanced Nursing, 65, 1527-1538. https://doi.org/10.1111/j.1365-2648.2009.04989.x

Hayashi, N., Wada, T., Hirai, H., Miyake, T., Matsuura, Y., Shimizu, N., Kurooka, H., \& Horiuchi, S. (2008). The Effects of Horticultural Activity in a Community Garden on Mood Changes. Environment Control in Biology, 46, 233-240.

Horowitz, J. A., \& Goodman, J. H. (2005). Identifying and Treating Postpartum Depres- 
sion. Journal of Obstetric, Gynecologic, \& Neonatal Nursing, 34, 264-273. https://doi.org/10.1177/0884217505274583

Kahn, R. S., Zuckerman, B., Bauchner, H., Homer, C., \& Wise, P. H. (2002). Women's Health after Pregnancy and Child Outcomes at Age 3 Years: A Prospective Cohort Study. American Journal of Public Health, 92, 1312-1318. https://doi.org/10.2105/AJPH.92.8.1312

Kam, M. C. Y., \& Siu, A. M. H. (2010). Evaluation of a Horticultural Activity Programme for Persons with Psychiatric Illness. Hong Kong Journal of Occupational Therapy, 20, 80-86. https://doi.org/10.1016/S1569-18611170007-9

Kellert, S. R., \& Wilson, E. O. (1993). The Biophilia Hypothesis. Washington, DC.: Island Press.

Kikuno, H., \& Kikuno, Y. (2015). Do Temperament of Child and Mother's Theory of Mind Influence on Child-Rearing Anxiety? Environment and Management, 21, 41-45.

Kim, B., Park, S., Song, J., \& Son, K. (2012). Horticultural Therapy Program for the Improvement of Attention and Sociality in Children with Intellectual Disabilities. HortTechnology Hortte, 22, 320-324. https://doi.org/10.21273/HORTTECH.22.3.320

Kim, Y. S., \& Park, S. A. (2016). Investigation of the Effects of Horticultural Activity Program for Mothers to Improve Relationship with Child. Journal of People Plants and Environment, 19, 585-593. https://doi.org/10.11628/ksppe.2016.19.6.585

Koga, Y., \& Iwasaki, Y. (2018). Exploring Emotional Experiences of the Healing Effects of Greenery: A Text Mining Analysis. Environmental Information Science Academic Research Papers, 32, 269-274.

Kotozaki, Y. (2014). Horticultural Therapy as a Measure for Recovery Support of Regional Community in the Disaster Area: A Preliminary Experiment for Forty Five Women Who Living Certain Region in the Coastal Area of Miyagi Prefecture. International Journal of Emergency Mental Health, 16, 284-287.

Kozhimannil, K. B., Adams, A., Soumerai, S., Busch, A., \& Huskamp, H. A. (2011). New Jersey's Efforts to Improve Postpartum Depression Care Did Not Change Treatment Patterns for Women on Medicaid. Health Affairs, 30, 293-301.

https://doi.org/10.1377/hlthaff.2009.1075

Kumar, R., \& Robson, K. M. (1984). A Prospective Study of Emotional Disorders in Childbearing Women. The British Journal of Psychiatry, 144, 35-47. https://doi.org/10.1192/bjp.144.1.35

Maller, C., Townsend, M., Pryor, A., Brown, P., \& Leger, L. S. (2006). Healthy Nature Healthy People: "Contact with Nature" as an Upstream Health Promotion Intervention for Populations. Health Promotion International, 21, 45-54. https://doi.org/10.1093/heapro/dai032

McLennan, J. D., Kotelchuck, M., \& Cho, H. (2001). Prevalence, Persistence, and Correlates of Depressive Symptoms in a National Sample of Mothers of Toddlers. Journal of the American Academy of Child \& Adolescent Psychiatry, 40, 1316-1323.

Milligan, C., Gatrell, A., \& Bingley, A. (2004). "Cultivating Health”: Therapeutic Landscapes and Older People in Northern England. Social Science and Medicine, 58, 1781-1793. https://doi.org/10.1016/S0277-9536(03)00397-6

Narama, M., Kanematsu, Y., Araki, A., Maru, M., Nakamura, N., Takeda, J., Shirahata, N., \& Kudo, Y. (1999). Validity and Reliability of the Japanese Version of the Parenting Stress Index. The Journal of Child Health, 58, 610-616.

Network NECCR (National Inst of Child Health \& Human Development, Early Child Care Research Network) (1999). Chronicity of Maternal Depressive Symptoms, Ma- 
ternal Sensitivity, and Child Functioning at 36 Months. NICHD Early Child Care Research Network. Developmental Psychology, 35, 1297-1310.

https://doi.org/10.1037/0012-1649.35.5.1297

O’Hara, M. W., \& Swain, A. M. (1996). Rates and Risk of Postpartum Depression-A Meta-Analysis. International Review of Psychiatry, 8, 37-54. https://doi.org/10.3109/09540269609037816

Okano, T., Murata, M., Masuji, S. et al. (1996). Reliability and Validity of the Japanese Version of the Edinburgh Postpartum Depression Self-Assessment Form (EPDS). Psychiatry Diagnostics, 7, 525-533.

Olfson, M., Marcus, S., Druss, B., Alan, P. H., \& Weissman, M. M. (2003). Parental Depression, Child Mental Health Problems, and Health Care Utilization. Medical Care, 41, 716-721. https://doi.org/10.1097/01.MLR.0000064642.41278.48

Page, M. (2008). Gardening as a Therapeutic Intervention in Mental Health. Nursing Times, 104, 28-30.

Pitt, B. (1968). “Atypical” Depression Following Childbirth. The British Journal of Psychiatry: the Journal of Mental Science, 114, 1325-1335. https://doi.org/10.1192/bjp.114.516.1325

Rappe, E. (2005). The Influence of a Green Environment and Horticultural Activities on the Subjective Well-Being of the Elderly Living in Long-Term Care.

Relf, D., \& Dorn, S. (1995). Horticulture: Meeting the Needs of Special Populations. HortTechnology, 5, 94-103. https://doi.org/10.21273/HORTTECH.5.2.94

Rowan, P. J., Duckett, S. A., \& Wang J. E. (2015). State Mandates Regarding Postpartum Depression. Psychiatric Services, 66, 324-328. https://doi.org/10.1176/appi.ps.201300505

Sempik, J., Aldridgem, J., \& Becker, S. (2003). Social and Therapeutic Horticulture: Evidence and Messages from Research. Leicestershire, UK: Centre for Child and Family Research, Loughborough University.

Simhi, M., Sarid, O., \& Cwikel, J. (2019). Preferences for Mental Health Treatment for Post-Partum Depression among New Mothers. Israel Journal of Health Policy Research, 8, Article number: 84. https://doi.org/10.1186/s13584-019-0354-0

Simon, P., \& Straus, C. (1998). Horticulture as Therapy: Principle and Practice. Binghamton, NY: Haworth Press.

Teychenne, M., Ball, K., \& Salmon, J. (2008). Physical Activity and Likelihood of Depression in Adults: A Review. Preventive Medicine, 46, 397-411. https://doi.org/10.1016/j.ypmed.2008.01.009

Ulrich, R. S., Simonst, R. F., Lositot, B. D., Fioritot, E., Milest, M. A., \& Zelsont, M. (1991). Stress Recovery during Exposure to Natural and Urban Environments. Journal of Environmental Psychology 11, 201-230. https://doi.org/10.1016/S0272-4944(05)80184-7

Waliczek, T. M., Bradley, J. C., Lineberger, R. D., \& Zajicek, J. M. (2000). Using a Web-Based Survey to Research the Benefits of Children Gardening. HortTechnology. 10, 71-76. https://doi.org/10.21273/HORTTECH.10.1.71

Weissman, M. M., Warner, V., Wickramaratne, P., Moreau, D., \& Olfson, M. (1997). Offspring of Depressed Parents. 10 Years Later. Arch Gen Psychiatry, 54, 932-940. https://doi.org/10.1001/archpsyc.1997.01830220054009

Yoshida, K., Yamashita, H., Conroy, S., Marks, M., \& Kumar, C. (2012). A Japanese Version of Mother-To-Infant Bonding Scale: Factor Structure, Longitudinal Changes and Links with Maternal Mood during the Early Postnatal Period in Japanese Mothers. Archives of Women's Mental Health, 15, 343-352.

https://doi.org/10.1007/s00737-012-0291-1 
Zaers, S., Waschke, M., \& Ehlert, U. (2008). Depressive Symptoms and Symptoms of Post-Traumatic Stress Disorder in Women after Childbirth. Journal of Psychosomatic Obstetrics and Gynecology, 29, 61-71. https://doi.org/10.1080/01674820701804324

Zinga, D., Phillips, S. D., \& Born, L. (2005). Postpartum Depression: We Know the Risks, Can It Be Prevented? Brazilian Journal of Psychiatry, 27, s56-s64.

https://doi.org/10.1590/S1516-44462005000600005 